\title{
Building bridges for climate change science
}

Science Writing and Climate Change, by Crispin C.Maslog, David Robie and Joel Adriano. Manila, Philippines: Asian Institute of Journalism and Communication, 2019. 106 pages. ISBN 9789718502198

$\mathrm{D}$

ESPITE the omnipresent threat of climate change, journalists still face an uphill battle communicating accurate and timely information to the public and governments, many of whom, sadly, still need to be convinced that the looming catastrophe is real. This book is aimed not just at print journalists and editors, but also teachers educating their students to write about science, trainers and broadcast and online writers.

As Maslog notes in the introduction, science communicators 'are the bridge between science and the scientists on the one hand and the people who will use their scientific discoveries on the other'.

Divided into two sections, this slim volume will be a useful guide for journalists reporting on the greatest threat to our planet.

The first part begins with an extremely useful section explaining what science is, what science does, how it works and how difficult the science beat can be. Journalists are expected to be Jacks (and Jills) of all trades, but 